\title{
Dynamics of unusual debris flows on Martian sand dunes
}

\author{
Hideaki Miyamoto, ${ }^{1,2}$ James M. Dohm, ${ }^{3}$ Victor R. Baker, ${ }^{1,3}$ Ross A. Beyer, ${ }^{1}$ \\ and Mary Bourke ${ }^{4}$
}

Received 20 April 2004; revised 28 May 2004; accepted 9 June 2004; published 8 July 2004.

[1] Gullies that dissect sand dunes in Russell impact crater often display debris flow-like deposits in their distal reaches. The possible range of both the rheological properties and the flow rates are estimated using a numerical simulation code of a Bingham plastic flow to help explain the formation of these features. Our simulated results are best explained by a rapid debris flow. For example, a debris flow with the viscosity of $10^{2} \mathrm{~Pa} \mathrm{~s}$ and the yield strength of $10^{2} \mathrm{~Pa}$ can form the observed deposits with a flow rate of $0.5 \mathrm{~m}^{3} / \mathrm{s}$ sustained over several minutes and total discharged water volume on the order of hundreds of cubic meters, which may be produced by melting a surface layer of interstitial ice within the dune deposits to several centimeters depth. INDEX TERMS: 1824 Hydrology: Geomorphology (1625); 1823 Hydrology: Frozen ground; 1625 Global Change: Geomorphology and weathering (1824, 1886); 6207 Planetology: Solar System Objects: Comparative planetology; 6225 Planetology: Solar System Objects: Mars. Citation: Miyamoto, H., J. M. Dohm, V. R. Baker, R. A. Beyer, and M. Bourke (2004), Dynamics of unusual debris flows on Martian sand dunes, Geophys. Res. Lett., 31, L13701, doi:10.1029/2004GL020313.

\section{Introduction}

[2] The observation of gullies and often associated debris aprons ignited discussions concerning the near-surface and surface presence of liquid water and its role in resurfacing the martian landscape in relatively recent times [Malin and Edgett, 2000]. Because liquid water is unstable under present atmospheric conditions [Clifford, 1993], any hypothesis explaining the formation of these features should address this significant aspect. Gullies have been identified on crater, trough and valley slopes, and also on aeolian dunes. Proposed hypotheses for gully formation include; surface water runoff from subsurface aquifers [Malin and Edgett, 2000], where discharge may be saline ground water [Knauth et al., 2000], melting of near-surface ice during past, warmer climatic conditions [Costard et al., 2002], and melting of water-rich snow packs [Christensen, 2003]. Hartmann et al. [2003] suggested that differential melting of surface ice could recharge local aquifers which, in turn, would trigger gully flow. Hypotheses that do not involve

\footnotetext{
${ }^{1}$ Lunar and Planetary Laboratory, University of Arizona, Tucson, Arizona, USA.

${ }^{2}$ Department of Geosystem Engineering, University of Tokyo, Tokyo, Japan.

${ }^{3}$ Department of Hydrology and Water Resources, University of Arizona, Tucson, Arizona, USA.

${ }^{4}$ Planetary Science Institute, Tucson, Arizona, USA.
}

Copyright 2004 by the American Geophysical Union. 0094-8276/04/2004GL020313\$05.00 water include dry flows of eolian dust and silt [Treiman, 2003]. For the aeolian dunes, the thawing of near surface ice is the preferred mechanism [Costard et al., 2002; Mangold et al., 2003; Reiss and Jaumann, 2003].

[3] Since most hypotheses assume that water-related flows carved the gullies, flow rate and water volume estimates are critical to modeling and testing these hypotheses. Possible quantitative estimation of these values based on the morphologic appearance of the gullies, however, is limited because the erosion rate of water-carved valleys, channels, and gullies is difficult to estimate, as is often the case in terrestrial investigations.

[4] Debris flow-like deposits are observed on the slopes of aeolian dunes in Russell impact crater, located in the boundary region separating Argyre and Hellas impact basins (54.5S and 12.7E). These deposits are significant because of their associated distinct levees, which provide morphologic clues to the physical conditions involved during their formation. In this work, we focus on the formation of these depositional features by analyzing their morphology using a numerical simulation model of a time-varying 2-D Bingham plastic flow. Our approach provides newly constrained flow rates and a more accurate assessment of flow rheology. Previous estimates of rheology [Mangold et al., 2003] used a 1-D analytical approach to estimate velocity from the small difference in thickness between both sides of a levee.

\section{Modeling of the Debris Flow}

\subsection{Major Modeling Assumptions}

[5] In this paper, a debris flow-like deposit refers to a complex feature, which includes the following primary components: lateral levees, a central channel, and sometimes a deposit at the terminus (Figure 1). The debris flowlike deposits in Figure 1 have an average length of about $1-2 \mathrm{~km}$ on an approximate $10^{\circ}$ slope. Detailed descriptions of their morphologies are found in Mangold et al. [2003].

[6] The deposits and associated channels follow the direction of the slope, which suggests that they are formed by gravity-driven processes [Mangold et al., 2003]. These features differ from those described by Malin and Edgett [2000], as each gully has a continuous lateral deposit, the channel displays an almost constant width, but does not terminate in a fan. We interpret this morphology to be highly diagnostic and suggest that the deposits are likely formed by a single major flow, though there might be other minor events that contribute. Combinations of these feature types are associated with the emplacement of debris or iceslush flows in cold environments on Earth [Rapp, 1985; Hartmann et al., 2003]. In those environments, the channels and levees form after the emplacements of the flow deposits: the formations of the channel and levees are primarily due to the subsidence of the flow surface related 

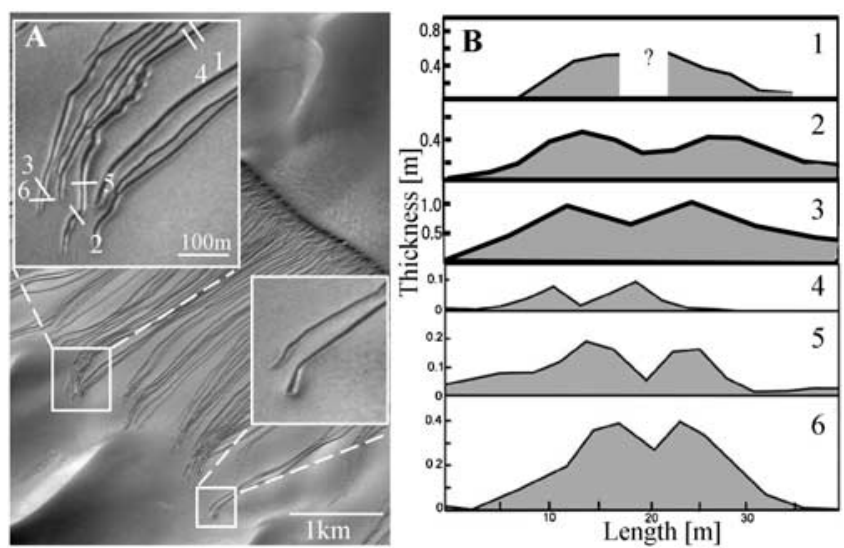

Figure 1. (a) MOC image M19-01170 with insets. Visible are debris flow-like deposits, which display gullies and levees, and the profile locations used in the photoclinometric measurements (white lines) of Figure 1B. (b). Topographic profiles across the debris flow-like deposits determined from photoclinometeric measurements (profiles for 4-6 are from Mangold et al. [2003]).

to a diminishing flow discharge and/or a differential degree of the basal erosion due to inhomogeneous velocity profiles [Johnson and Rodine, 1984; Corominas, 1995]. Their formations may also be associated with later modification including slower drainage and evaporation of pore water or collapse of the ice-rich central part due to sublimation, as suggested for the levee formation of Icelandic debris flows [Hartmann et al., 2003].

[7] Here, we assume that the channels of Russell crater dunes are formed by processes similar to those described above i.e., that the channels and levees form after the emplacement of the debris flow-like deposit. We model the emplacement of the lower part of the debris flow-like deposit as a single flow and not the channel formation, the trigger mechanism, or the erosive processes, which includes channel formation. As often performed for terrestrial debris flows, we modeled particularly at a break in slope where the flow is considered to achieve steady state flow conditions, including constant width and thickness. In this case, we can assume that a particular flow has constant rheological properties and flow rate along the modeled area. This assumption, although an oversimplification, is acceptable as individual deposits display almost constant width along the flow, whereas it has been shown that differences in both the rheological property and the flow rate will largely change the width of a flow [Miyamoto and Sasaki, 1998].

\subsection{Bingham Approximation}

[8] We do not assume any particular flow-related process for the formation of the debris flow-like deposits. Rather, we assume that a deposit is formed by a plastic flow [Mangold et al., 2003]. In this work, we adopt the Bingham approximation for the rheology model of a flow, because it is the simplest and the most widely applied model to assess various flow types with varying concentrations of volatiles, which include dry granular flows, at laboratory to geological scales (see references in Miyamoto et al., 2004). We recognize that the Bingham model might not be optimal for both debris and glacial flows, however, we adopted because the Bingham approximation enables us to test several hypotheses at the same level.

[9] We measured the thickness of deposits using a profiling photoclinometry technique (Figure 1) based on the Beyer et al. [2003] point photoclinometry technique. The estimated values in this investigation are from the minimum pixel haze estimate, which will produce upper slope limits. Therefore, the modeled relief may be an over estimate of the true relief. Our measurements are about 3 to 5 times larger than the values estimated by Mangold et al. [2003], which may give the lower slope limits. Flow thicknesses ranging from $0.1-1.0 \mathrm{~m}$ for flows on an average $10^{\circ}$ slope are used to constrain the model. Assuming that the thickness of the levee or the terminal deposit is comparable to the thickness of the deposits at the time of emplacement, the yield strength of the flow can be estimated by balancing it with the shear stress at the base, as discussed by Johnson and Rodine [1984]. For an estimated maximum flow thickness of $0.1-1 \mathrm{~m}$ and an assumed density of $1500 \mathrm{~kg} / \mathrm{m}^{3}$, an estimated yield strength value will be on the order of $10^{2} \mathrm{~Pa}-10^{3} \mathrm{~Pa}$, which gives the minimum and the maximum values used in the numerical modeling of this investigation. These values are in the range of estimations by Mangold et al. [2003].

\subsection{Numerical Simulations of Bingham Flows}

[10] We performed numerical simulations of a Bingham fluid [Miyamoto and Sasaki, 1998] with a small modification on the expression for the critical thickness to increase the accuracy [Miyamoto et al., 2004]. This model is based on a Bingham-approximation version of the shallow-water equations for a slow-moving flow and is validated against terrestrial flows [Miyamoto and Sasaki, 1997]. In this model, volumetric fluxes in the $\mathrm{x}$ and $\mathrm{y}$ directions are calculated separately and placed into the continuity equation in order to calculate a time sequential movement of the flow. We neglect the interactions between the flow and underlying materials, since we model the depositional part of the flow only. Simulations were done with varying viscosities and supply rates over a $10^{\circ}$ slope to determine parameter values that best represent the flow characteristics (see Figures 2, 3, and 4 and captions). All flows are supplied at a point source whose area is $4 \mathrm{~m}^{2}$. Note that the size of the source area will not largely influence the results if it is much narrower than the width of the flow.

[11] Summary of the results include: (1) a flow with very low viscosity $(<10 \mathrm{~Pa} \mathrm{~s}$; as low as or smaller than a typical debris slurry) does not achieve the observed flow width (Figure 2), even if we assume an unrealistically high flow rate for a possible gravity current such as a debris flow and an ice-slush flow; (2) a flow with a very high viscosity $\left(>10^{12} \mathrm{~Pa} \mathrm{~s}\right.$; greater than an ice-slush flow and as high as a glacier) always displays a greater width than those observed (Figure 2); and (3) a wide range of viscosity values can account for the observed widths, heights, and formation time of the debris flow-like deposits if the flow rate is properly balanced with the viscosity value (Figure 2).

\section{Discussions and Implications}

[12] The estimated viscosity values in this work range from $10 \mathrm{~Pa} \mathrm{~s}$ to $10^{11} \mathrm{~Pa}$ s. Therefore, pure water or a diluted flow with very low solid content is not considered as a sole 

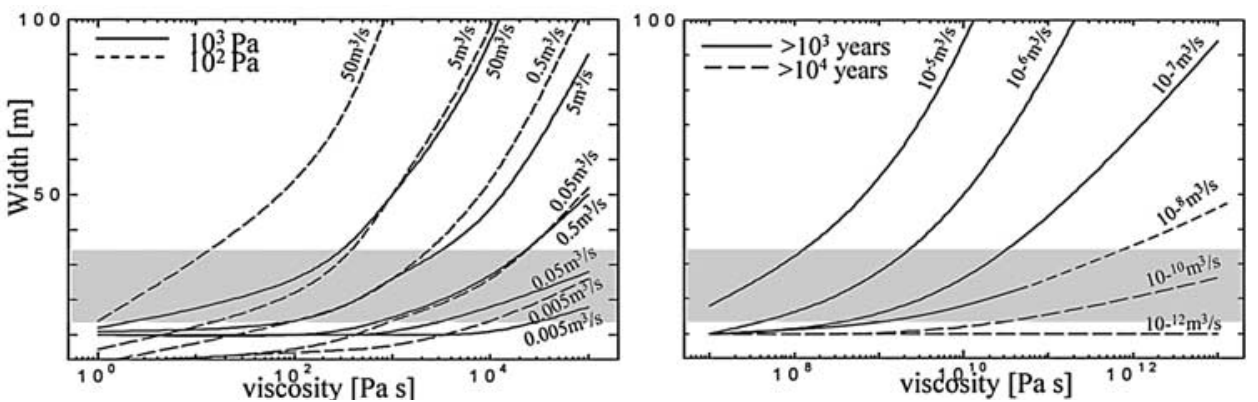

Figure 2. Width vs. viscosity for different yield strengths and supply rates. Flow widths ranging from about $15 \mathrm{~m}$ to $35 \mathrm{~m}$ are used to constrain the possible values of viscosity and supply rate based on observations using MOC imagery (gray highlights the estimated widths of debris flow-like deposits). The range of the supply rate for the calculations is from $10^{-12} \mathrm{~m}^{3} / \mathrm{s}$ to $50 \mathrm{~m}^{3} / \mathrm{s}$. Left, results determined with lower viscosity flows using a yield strength of $10^{3} \mathrm{~Pa}$ (solid lines) and $10^{2} \mathrm{~Pa}$ (dashed lines). Right, Larger viscosity results using a yield strength of $10^{3} \mathrm{~Pa}$. Time required to form a deposit with a typical length of debris flow-like deposits $(600 \mathrm{~m})$ is more than $10^{3}$ years (solid lines) or more than $10^{4}$ years $($ dashed lines).

agent in the emplacement of the debris flow-like deposits. Highly viscous flows, such as ice and rock glaciers, are not likely candidates for the formation of these deposits. In addition, a dry granular flow is not likely because of the friction angle of sand grains (typically larger than $25^{\circ}$ ).

[13] The simulated results show that higher viscosity flows $\left(10^{7} \sim 10^{11} \mathrm{~Pa}\right.$ s) may account for the deposits. However, flows with viscosities higher than $10^{7} \mathrm{~Pa}$ s require durations of more than $10^{3}$ years and extremely low flow rates. These are considered unlikely because there are no terrestrial analogs to explain both the viscosity and the duration. Also, the low and long-lasting flow rate may be unrealistic considering current martian conditions. Although there might be several ways to explain a high viscosity value when considering an ice-rich slush and gelifluction, we consider this interpretation to be highly questionable.

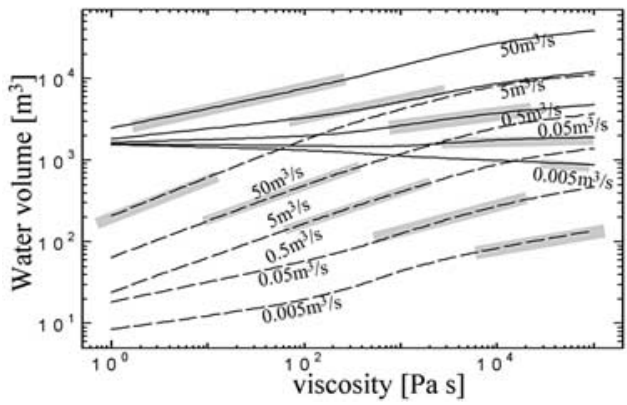

Figure 3. Diagram shows the water volume necessary to form a debris flow-like deposit that has a length of $600 \mathrm{~m}$. Results determined using a yield strength of $10^{3} \mathrm{~Pa}$ (solid lines) and $10^{2} \mathrm{~Pa}$ (dashed lines). The range of the supply rate is from $0.005 \mathrm{~m}^{3} / \mathrm{s}$ to $50 \mathrm{~m}^{3} / \mathrm{s}$. Gray highlighted areas show the possible ranges of parameters constrained by both widths (Figure 2) and thicknesses. Water volume is calculated by total volume from the simulations to achieve the length of $600 \mathrm{~m}$, and a rough estimate of water contents for viscosities $\left(10 \%\right.$ for $10^{5} \mathrm{~Pa} \mathrm{~s}, 20 \%$ for $10^{4} \mathrm{~Pa} \mathrm{~s}, 30 \%$ for $10^{3} \mathrm{~Pa} \mathrm{~s}, 40 \%$ for $10^{2} \mathrm{~Pa} \mathrm{~s}, 45 \%$ for $10 \mathrm{~Pa} \mathrm{~s}$, and $50 \%$ for $1 \mathrm{~Pa} \mathrm{~s}$ ). Though the estimates of the water contents are based on the general trend of that of terrestrial debris flows, the estimated values should be considered as order of magnitude estimates.
[14] On the other hand, a rapid debris flow origin [Mangold et al., 2003] is most consistent with our results. The lower end member of the estimated viscosity value, $10^{2}-10^{5} \mathrm{~Pa} \mathrm{~s}$, and estimated yield strength and flow rate, $10^{2}-10^{3} \mathrm{~Pa}$ and $0.005-5 \mathrm{~m}^{3} / \mathrm{s}$, respectively, are consistent with typical values of terrestrial debris flows. The existence of rapid debris flows over sand dunes implies an external origin of water, since subsurface seepage from an aquifer is unlikely near the dune crests [Mangold et al., 2003]. This has been explained by the melting of water ice in the top few meters of the martian subsurface at high obliquity [Costard et al., 2002]; in this case, the formation time of the deposits would be well shorter than a few hours. Considering this short time, our simulated results show that the estimated viscosity values would be lower than $10^{3} \mathrm{~Pa} \mathrm{~s}$ (Figure 4).

[15] In the case of the rapid debris flow, the minimum estimated volume of water from our calculations is only $\sim 100 \mathrm{~m}^{3}$. This amount of water is not a large volume: if we assume that the water is from the eroded area, which is about $1 \mathrm{~km}$ by $20 \mathrm{~m}$ width from MOC images, and that this

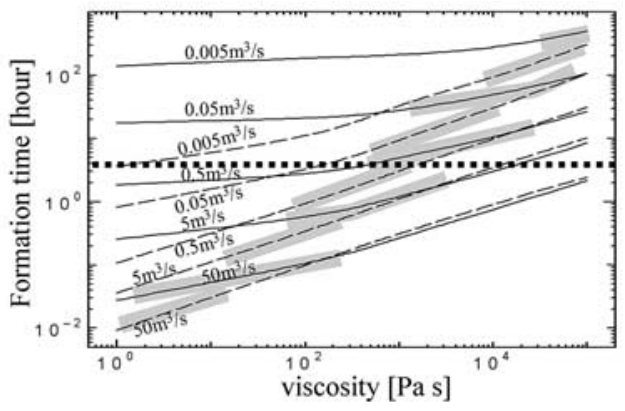

Figure 4. This diagram displays the time of formation of debris flow-like deposits for different viscosities and supply rates. Results determined using a yield strength of $10^{3} \mathrm{~Pa}$ (solid lines) and $10^{2} \mathrm{~Pa}$ (dashed lines). The range of the supply rate is from $0.005 \mathrm{~m}^{3} / \mathrm{s}$ to $50 \mathrm{~m}^{3} / \mathrm{s}$. Gray highlighted areas show the possible ranges of parameters constrained by both widths (Figure 2) and thicknesses. Dotted line indicates a possible duration of meltwater during the daytime at high obliquity. 
area was covered by sand and ice mixture with ice content of $50 \%$, only several centimeters melting depth would produce $\sim 100 \mathrm{~m}^{3}$ of water. Therefore, in the periods of high obliquity, for example, sufficient warming on pole-facing slopes may melt near-surface ice deposits and increase pore pressure near the surface. Explanations for the origin of the near-surface ice include: (1) diffusion from the atmosphere [Mellon and Jakosky, 1995] (2) burial of precipitated snow and frost layers by rapidly aggrading sand layers [Calkin and Rutford, 1974; Bourke et al., 2004] (3) Blown snow transported simultaneously with sedimentary particles and deposited as niveo-aeolian deposits [McKenna Neuman, 1993; Bourke et al., 2004].

[16] Our interpretation of the results presented here include the following sequence of events: (1) melt water at the near-surface of the dune causes a decrease in the critical strength to produce a sufficient amount of material to slip, triggering a debris flow, as seen in terrestrial debris flows, (2) the debris flow continues down the slope, collecting the sand and water/ice mixture, and (3) the flow begins to slow at the break in slope and the internal highervelocity flow material dissects the debris flow material forming the channel and levees.

[17] This process can explain why the gullies initiate at nearly the same elevation where the slope is greatest and therefore easiest for surface materials to slip. The rheological property of the debris flow is probably controlled by the surface material, which is the mixture of sand and water. This is consistent with first, that each deposit displays an almost constant width along its length without branches and second, that a single debris flow-like deposit displays almost the same geometric pattern as another in the same area. This could explain why many gullies in the dune field of Russell crater display similar morphologies to those in other dune fields. Although terrestrial data show that small difference in water concentration can significantly change the morphology of terrestrial debris flows. The spacing of each debris flows probably reflects the uniformity of the property of the slope, possibly due to the homogeneity of both the sand particles and the volumetric fraction of ice in the dune material, and melting rate of the deposited ice by insolation.

[18] The debris flow-like deposits usually show simple structures rather than episodic debris aprons. This may be due to the depletion of the volatile along the flow. The formation of the dune might be so recent that there might be no chance for ice to recharge after the formation of deposits, because obliquity varies from 15 to $>35$ on timescales of $10^{5}$ to $10^{6}$ years [Ward, 1979].

[19] Acknowledgments. We thank L. Bleamaster for helpful discussions. We are grateful for helpful reviews by two anonymous reviewers.
This study was supported in part by JSPS Postdoctoral Fellowships for Research Abroad (to HM) and NASA MDAP NAG5-11090 (to MB).

\section{References}

Beyer, R. A., A. S. McEwen, and R. L. Kirk (2003), Meter-scale slopes of candidate MER landing sites from point photoclinometry, J. Geophys. Res., 108(E12), 8085, doi:10.1029/2003JE002120.

Bourke, M. C., J. Bullard, and O. Barnouin-Jha (2004), Aeolian sediment transport pathways and aerodynamics at troughs on Mars, J. Geophys. Res., 109, doi:10.1029/2003JE002155, in press.

Calkin, P. E., and R. H. Rutford (1974), The sand dunes of Victoria Valley, Antarctica, Geogr. Rev., 64(2), 189-216.

Christensen, P. R. (2003), Formation of recent Martian gullies through melting of extensive water-rich snow deposits, Nature, 422, 45-48.

Clifford, S. M. (1993), A model for the hydrologic and climatic behavior of water on Mars, J. Geophys. Res., 98, 10,973-11,016.

Corominas, J. (1995), Evidence of basal erosion and shearing as mechanisms contributing the development of lateral ridges in mudslides, flow-sides, and other flow-like gravitational movements, Eng. Geol., 39, 45-70.

Costard, F., F. Forget, N. Mangold, and J. P. Peulvast (2002), Formation of recent Martian debris flows by melting of near-surface ground ice at high obliquity, Science, 295, 110-113.

Hartmann, W. K., T. Thorsteinsson, and F. Sigurdsson (2003), Martian hillside gullies and Icelandic analogs, Icarus, 162, 259-277.

Johnson, A. M., and J. R. Rodine (1984), Debris flows, in Slope Instability, edited by D. Brunsden and D. B. Prior, pp. 257-361, John Wiley, Hoboken, N. J.

Knauth, L. P., S. Klonowski, and D. M. Burt (2000), Ideas about the surface runoff features on Mars, Science, 290, 711-712.

Malin, M. C., and K. S. Edgett (2000), Evidence for recent groundwater seepage and surface runoff on Mars, Science, 288, 2330-2335.

Mangold, N., F. Costard, and F. Forget (2003), Debris flows over sand dunes on Mars: Evidence for liquid water, J. Geophys. Res., 108(E4), 5027, doi:10.1029/2002JE001958.

McKenna Neuman, C. (1993), A review of aeolian transport processes in cold environments, Progr. Phys. Geogr., 17(2), 137-155.

Mellon, M. T., and B. M. Jakosky (1995), The distribution and behavior of Martian ground ice during past and present epochs, J. Geophys. Res., 100, 11,781-11,799.

Miyamoto, H., and S. Sasaki (1997), Simulating lava flows by an improved cellular automata method, Comput. Geosci., 23, 283-292.

Miyamoto, H., and S. Sasaki (1998), Numerical simulations of flood basalt lava flows: Roles of some parameters on flow morphologies, J. Geophys. Res., 103, 27,489-27,502.

Miyamoto, H., J. M. Dohm, R. A. Beyer, and V. R. Baker (2004), Fluid dynamical implications of anastomosing slope streaks on Mars, J. Geophys. Res., 109, E06008, doi:10.1029/2003JE002234.

Rapp, A. (1985), Extreme rainfall and rapid snowmelt as causes of mass movements in high latitude mountains, in Field and Theory, Lectures Geocryology, edited by M. Church and O. Slaymaker, pp. 36-56, Univ. of B. C. Press, Vancouver, B. C., Canada.

Reiss, D., and R. Jaumann (2003), Recent debris flows on Mars: Seasonal observations of the Russell Crater dune field, Geophys. Res. Lett., 30(6), 1321, doi: $10.1029 / 2002$ GL016704.

Treiman, A. H. (2003), Geologic setting of Martian gullies: Implications for their origins, J. Geophys. Res., 108(E4), 8031, doi:10.1029/ 2002JE001900.

Ward, W. R. (1979), Present obliquity oscillations of Mars: Fourth-order accuracy in orbital $e$ and I, J. Geophys. Res., 84, 237-241.

V. R. Baker, R. A. Beyer, and H. Miyamoto, Lunar and Planetary Laboratory, University of Arizona, Tucson, AZ 85721, USA. (miyamoto@ geosys.t.u-tokyo.ac.jp)

M. Bourke, Planetary Science Institute, Tucson, AZ, USA.

J. M. Dohm, Department of Hydrology and Water Resources, University of Arizona, Tucson, AZ, USA. 